\title{
APRESENTAÇÃO DOSSIÊ: DOCÊNCIA NO ENSINO SUPERIOR
}

\author{
PRESENTACIÓN DEL DOSSIER: LA DOCENCIA EN LA ENSEÑANZA SUPERIOR
}

DOSSIER PRESENTATION: TEACHING IN HIGHER EDUCATION

\author{
Mirlene Ferreira Macedo DAMÁZIO ${ }^{1}$ \\ Adriana CAMPANI ${ }^{2}$ \\ Katiuscia C. Vargas ANTUNES ${ }^{3}$
}

RESUMO: A docência no ensino superior deve ser o objeto de investigação das instituições e seus gestores, em virtude da importância que tem para os pilares do ensino, da pesquisa e da extensão. Vamos tratar neste dossiê temático sobre o que está acontecendo, neste momento, com relação à docência, envolvendo as nuances dessa atuação profissional nos campos político, pedagógico e sociocultural. O docente do ensino superior ocupa-se e cumpre uma extensa programação profissional, que ultrapassa o elaborar e o ministrar aulas. No dia a dia da universidade, os professores têm como responsabilidade a participação e a coordenação de projetos de pesquisa, preparação de relatórios, orientações de trabalhos de conclusão de curso, produção de artigos científicos e outras atividades, sustentando o tripé do ensino, da pesquisa e da extensão. Exercer essas atividades profissionais exige tempo, energia e dedicação. Diante do exposto, existe também a preocupação de melhorar a formação pedagógica do docente no ensino superior, que é realizada nos cursos de pós-graduação stricto sensu e tem se mostrado uma alternativa momentaneamente válida, entretanto existem controvérsias e questionamentos.

PALAVRAS-CHAVE: Docência. Ensino superior. Formação pedagógica.

RESUMEN: La docencia en la enseñanza superior debería ser objeto de investigación de las instituciones y sus gestores, debido a su importancia para los pilares de la enseñanza, la investigación y la extensión. Trataremos en este dossier temático lo que está sucediendo, en

\footnotetext{
${ }^{1}$ Universidade Federal da Grande Dourados (UFGD), Dourados - MS - Brasil. Professora Adjunto. Chefe do Núcleo Multidisciplinar para Inclusão e Acessibilidade da Reitoria/UFGD. Gestora na UFGD do Observatório Internacional, Inclusão, Interculturalidade e Inovação Pedagógica - OIIIIPe no Ensino Superior por meio do Acordo de Cooperação entre a UFRJ/UFGD, mais 18 universidades, sendo 5 internacionais. Coordenadora do Curso de Especialização em Educação Especial FAED/UFGD. ORCID: http://orcid.org/0000-0001-7449-2261. E-mail: psmirlenefm@gmail.com

${ }^{2}$ Universidade do Vale do Acaraú (UVA), Sobral - CE - Brasil. Professora Efetiva, Pró-Reitora Adjunta de Ensino de Graduação, Procuradora Institucional (P.I.) e membro da Comissão Própria de Avaliação - CPA (UVA). Coordena na UVA o Observatório Internacional de Inclusão, Interculturalidade e Inovação Pedagógica no Ensino Superior - OIIIIPe por meio do Acordo de Cooperação entre a UFRJ/UVA. ORCID: https://orcid.org/0000-0002-4524-7694. E-mail: campaniadriana@gmail.com

${ }^{3}$ Universidade Federal de Juiz de Fora (UFJF), Juiz de Fora - MG - Brasil. Professora do Departamento de Educação, do Mestrado em Gestão e Avaliação da Educação Pública (PPGP/CAED/UFJF) e pesquisadora do Núcleo de Estudos e Pesquisas em Educação e Diversidade - NEPED/UFJF. Coordena, ainda, o Núcleo de Apoio à Inclusão da Universidade Federal de Juiz de Fora e é Membro do Observatório Internacional Interculturalidade, inclusão e Inovação pedagógica (OIIIP). ORCID: https://orcid.org/0000-0003-2861-551X. Email: katiuscia.vargas@educacao.ufjf.br
} 
este momento, en relación con la enseñanza, implicando los matices de esta actuación profesional en el ámbito político, pedagógico y sociocultural. El profesor de educación superior está a cargo y cumple un extenso programa profesional, que va más allá de la preparación y la enseñanza de las clases. En la vida cotidiana de la universidad, los profesores son responsables de la participación y coordinación de los proyectos de investigación, la preparación de informes, la orientación de los trabajos de conclusión de los cursos, la producción de artículos científicos y otras actividades, apoyando el trípode de la enseñanza, la investigación y la extensión. El ejercicio de estas actividades profesionales requiere tiempo, energía y dedicación. En vista de lo anterior, también existe la preocupación de mejorar la formación pedagógica de los profesores de la enseñanza superior, que se lleva a cabo en cursos de postgrado stricto sensu y ha demostrado ser una alternativa momentáneamente válida, aunque hay controversias y preguntas.

PALABRAS CLAVE: Docencia. Educación superior. Formación pedagógica.

ABSTRACT: Teaching in higher education should be the object of research of the institutions and their managers, due to its importance for the pillars of teaching, research and extension. We will deal in this thematic dossier with what is happening, at this moment, in relation to teaching, involving the nuances of this professional performance in the political, pedagogical and socio-cultural fields. The higher education professor is in charge of and fulfills an extensive professional program, which goes beyond the elaboration and teaching of classes. In the daily life of the university, the professors are responsible for the participation and coordination of research projects, preparation of reports, orientation of course conclusion works, production of scientific articles and other activities, supporting the tripod of teaching, research and extension. Exercising these professional activities requires time, energy and dedication. In view of the above, there is also a concern to improve the pedagogical training of teachers in higher education, which is carried out in postgraduate courses stricto sensu and has proven to be a momentarily valid alternative, however there are controversies and questions.

KEYWORDS: Teaching. Higher education. Pedagogical training.

Ao idealizarmos este dossiê temático, Docência no ensino superior, objetivamos sistematizar produções relevantes, visando a socialização e a divulgação de conhecimentos produzidos por diversas pesquisas e experiências nas universidades e pelo Observatório Internacional Inclusão, Interculturalidade e Inovação Pedagógica (OIIIIPe). Este dossiê foi organizado com 16 artigos nacionais, envolvendo o ensino, a pesquisa e a extensão da graduação e pós-graduação. Nessa perspectiva, o dossiê envolveu as dimensões da formação de professores com as especificidades do ensino superior, permeando os saberes da didática, metodologia de ensino e as práxis pedagógicas.

Assim, o primeiro artigo, denominado "Ensino superior: entre docências e violências", de Mônica Pereira dos Santos, Sandra Cordeiro de Mel e Mylene Cristina 
Santiago, leva-nos a refletir sobre dados da Comissão de Direitos Humanos e Combate à Violência na Universidade Federal do Rio de Janeiro e na Universidade Federal de Juiz de Fora. Objetiva analisar e discutir as violências nas relações entre professores e alunos em uma perspectiva omnilética. Os resultados salientam a urgência de propostas de combate às violências.

As autoras do segundo artigo, Cassiano Caon Amorim e Katiuscia C. Vargas Antunes, falam-nos sobre os desafios da docência no Ensino Superior perante a inclusão de pessoas com deficiência. $\mathrm{O}$ artigo refletiu sobre o acesso de estudantes com deficiência no ensino superior a partir da Lei 13.409/2016. A inclusão de pessoas com deficiência no ensino superior é complexa, principalmente acerca da atuação do professor, no que tange à capacidade de ressignificar e modificar sua prática pedagógica na ambiência da sala de aula.

O terceiro artigo, Mirlene Damázio e Sandra Souza, tratam sobre o resultado parcial de uma pesquisa de natureza qualitativa, denominada “ "Chão da sala de aula" no ensino superior: metodologia dos professores". Nesse artigo, relatam acerca do chão da sala de aula, envolvendo a metodologia de ensino do professor. Concluem que urge ocorrerem modificações no contexto do chão da sala de aula no ensino superior, de um modelo excludente para inclusivo. Salientam que o caminho metodológico inclusivo requer "jeitos diferentes" no processo pedagógico e finalizam dizendo que o ensino superior necessita uma mudança de paradigma pedagógico.

O quarto artigo, "Docência nos cursos de formação de professores que ensinam matemática: o que as pesquisas revelam?", de Angélica da Fontoura Garcia Silva, Edvonete Souza de Alencar e Maria Elisabette Brisola Brito Prado, teve como objetivo analisar os resultados encontrados em pesquisas brasileiras de cursos de formação de professores no período de 2014-2018. Foi realizado um levantamento bibliográfico na plataforma de dissertações e teses da Capes. O estudo apontou, de modo geral, a necessidade de incentivo de mais pesquisas abordarem a questão da formação do professor.

Com o quinto artigo, "Inclusão de estudantes com deficiência no Ensino Superior: exigências de reconfiguração de saberes, concepções e práticas”, de Francisca Geny Lustosa e Disneylândia Maria Ribeiro, somos levados a compreender sobre o desafio da inclusão de estudantes com deficiência, enfatizando as políticas de acesso. A pesquisa é com abordagem qualitativa do tipo exploratória e envolve relatos de estudantes da UFC, da UECE e da UERN, realizada por meio de entrevistas semiestruturadas. Os resultados indicam a necessidade de políticas institucionais intencionais para inclusão, resolvendo as barreiras existentes, acompanhadas de boas práticas pedagógicas dos professores. 
O sexto artigo, "O estudo do meio como processo gerador do ensino, pesquisa e extensão", de Álamo Pimentel, propõe um estudo do meio como processo gerador da indissociabilidade entre o ensino, a pesquisa e a extensão universitária, envolvendo concepções pedagógicas de Célestin Freinet e Anísio Teixeira. Considerando ações inovadoras no Ensino Superior, o texto descreve e analisa uma experiência realizada na Universidade Federal do Sul da Bahia. Os exemplos do estudo do meio na UFSB ressaltam que o meio é um lugar da sala de aula, ou seja, do ensino, da pesquisa e da extensão universitários.

O sétimo artigo, "Reserva de vagas em universidades públicas estaduais: implicações para a docência universitária”, de Ana Cristina Silva Soares, Valéria de Oliveira, objetiva analisar a articulação entre a reserva de vagas de duas instituições públicas de ensino superior e a docência universitária para práticas pedagógicas; visa combater a desigualdade racial, social e cultural e garantir a igualdade com equidade; questiona a docência universitária de duas instituições de ensino superior sobre as experiências das reservas de vagas; evidencia que política de ação na UVA e UERJ tem ampliado o acesso de graduandos oriundos de escolas públicas.

O oitavo artigo, de Cyntia de Souza Bastos Rezende e Mônica Vasconcellos, "Rememorar é transcender: um diálogo com licenciandos do Grupo PET Conexões de Saberes da Universidade Federal Fluminense", tem por objetivo analisar narrativas de licenciandos acerca das contribuições do grupo PET para a formação e a produção de saberes profissionais. Os resultados evidenciam produção e articulação de saberes, compartilhamento de ações, ressignificação dos conhecimentos sobre sua futura profissão e ampliam e reforçam as chances de permanência na universidade.

O nono artigo, "Processos identitários de docentes universitários: espaço e tempo da formação", de Filadelfia de Carvalho Sena e Jônia Tírcia Parente Jardim Albuquerque, leva-nos a reflexões sobre o mundo globalizado. O objetivo desse artigo foi compreender, no percurso de formação de professores universitários, as implicações sobre a construção da identidade docente. Pesquisa qualitativa e abordagem (auto)biográfica. Foram narradas quatro histórias de professoras universitárias da Universidade Estadual Vale do Acaraú, em Sobral $\mathrm{CE}$, identificando-se a fragilidade, a pluralidade e a mobilidade das identidades construídas ao longo da vida de cada professora.

No décimo artigo, de Luiz Andrade, sobre "Universidade: autonomia, diversidade e inclusão", o principal objetivo foi articular três temas inerentes à universidade: autonomia, diversidade e inclusão. Essas conversações são multidimensionais, diversas e inclusivas. 
Menciona-se que a universidade deve ser entendida como processualidade instituinte, e não como realidade instituída, gerando intervenções inter e transdisciplinares.

“Contribuição da extensão para uma docência universitária inovadora: um estudo a partir do programa de ligas da enfermagem da universidade estadual vale do Acaraú" é o décimo primeiro artigo elaborado por Rejane Maria Gomes da Silva, Adriana Campani e Jaqueline Gomes Negreiros. As autoras demonstraram que, mais do que novas tecnologias da informação/comunicação e metodologias ativas de ensino-aprendizagem, a inovação pedagógica na universidade requer rupturas epistemológicas. Identificaram que a experiência de extensão contribui para um processo inovador, o fortalecimento da interculturalidade e a inclusão de saberes.

No décimo segundo artigo, "Desafios na formação de professores em um mundo conectado: representações, práticas e linguagens inovadoras”, de Rejany dos Santos Dominick, Walcéa Barreto Alves e Marcia Maria e Silva, somos levados a refletir sobre a emergência de estudos sistemáticos acerca da cibercultura e tecnologias informacionais. Dialogou-se com os conceitos inovação pedagógica, inclusão digital, cultura hacker e inteligência coletiva. Esse trabalho é o resultado de três rodas de conversa com estudantes universitários e professores do ensino superior: consideram necessárias maior clareza e reflexão crítica sobre as implicações das políticas educacionais e práticas docentes no mundo conectado.

No décimo terceiro artigo, de Simão Alberto, Reginaldo Leandro Plácido e Ivonete Telles Medeiros Plácido, sobre “A formação docente e o tecnicismo pedagógico: um desafio para a educação contemporânea", professores da docência do Ensino Superior são desafiados a reavaliar a prática docente. $O$ trabalho oportuniza uma reflexão a respeito da prática pedagógica, busca provocar uma discussão sobre o professor reflexivo e aborda o pensamento newtoniano-cartesiano, o tecnicismo e a inserção das tecnologias.

O décimo quarto artigo, de Sônia Regina de Souza Fernandes e Filomena Lucia Gossler Rodrigues Silva, sobre o "Trabalho docente e inovação pedagógica no contexto dos institutos federais: a experiência da formação continuada por meio da aprendizagem baseada em problemas e da metodologia da problematização", objetiva contribuir com a reflexão da docência no ensino superior e a inovação pedagógica por meio das metodologias ativas. Utiliza a metodologia da aprendizagem baseada em problemas (ABP/PBL) e a metodologia da problematização (MP). Os resultados revelam que inovar pedagogicamente exige dialogicidade e problematização da realidade. 
No último artigo, de Vera Lúcia Messias Fialho Capellini, Marcia Miranda Silveira Bello e Verônica Lima dos Reis, sobre a "Aprendizagem cooperativa no ensino superior: relato de uma experiência", objetiva-se relatar a experiência vivenciada na disciplina Prática de Ensino na Educação Infantil. Participaram 35 acadêmicos da Universidade Estadual Paulista "Júlio de Mesquita Filho". A aprendizagem cooperativa contribuiu para a formação dos estudantes, sendo ela diferenciada, participativa, colaborativa e solidária, garantindo uma perspectiva inclusiva.

Diante do exposto, os artigos apresentados neste dossiê ajudarão a comunidade acadêmica a lidar com as nuances do ensino superior, favorecendo o enriquecimento da práxis pedagógica e o melhor desenvolvimento dos estudantes.

\section{Como referenciar este artigo}

DAMÁZIO, M. F. M.; CAMPANI, A.; ANTUNES, K. C. V. Apresentação dossiê docência no ensino superior. Revista Ibero-Americana de Estudos em Educação, Araraquara, v. 15, n. esp. 2, p. 1443-1448, ago. 2020. e-ISSN: 1982-5587. DOI: https://doi.org/10.21723/riaee.v15iesp2.13974

Submetido em: 30/08/2019

Revisões requeridas: 30/11/2019

Aprovado em: 02/02/2020

Publicado em: 01/08/2020 